\title{
Erratum to: Evaluation of a surgical service in the chronic phase of a refugee camp: an example from the Thai-Myanmar border
}

Chathika K. Weerasuriya', Saw Oo Tan', Lykourgos Christos Alexakis ${ }^{4}$, Aung Kaung Set ${ }^{1}$, Marcus J. Rijken ${ }^{1}$, Paul Martyn ${ }^{1}$, François Nosten ${ }^{1,2,3}$ and Rose McGready ${ }^{1,2,3^{*}}$

\section{Erratum}

Unfortunately, the original version of this article [1] contained an error.

Lykourgos Christos Alexakis was incorrectly assigned affiliation "Mahidol-Oxford Tropical Medicine Research Unit (MORU), Mahidol University, Bangkok 10400, Thailand" (affiliation number 2), instead of "Aide Médicale Internationale (AMI), Mae Sot, Tak, Thailand" (affiliation number 4 in this erratum).

All affiliations are correctly included in full in this erratum.

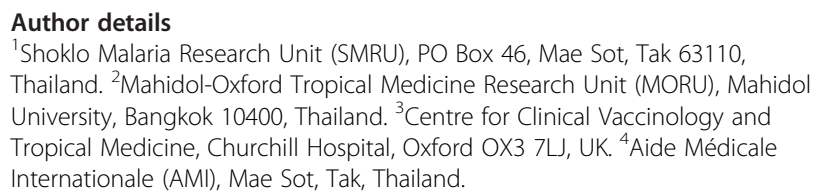

\section{Reference}

1. Weerasuriya CK, Tan SO, Alexakis LC, Set AK, Rijken MJ, Martyn P, et al. Evaluation of a surgical service in the chronic phase of a refugee camp: an example from the Thai-Myanmar border. Confl Health. 2012;6:5. doi:10.1186/ 1752-1505-6-5.

\footnotetext{
* Correspondence: rose@shoklo-unit.com

${ }^{1}$ Shoklo Malaria Research Unit (SMRU), PO Box 46, Mae Sot, Tak 63110, Thailand

${ }^{2}$ Mahidol-Oxford Tropical Medicine Research Unit (MORU), Mahidol University, Bangkok 10400, Thailand

Full list of author information is available at the end of the article

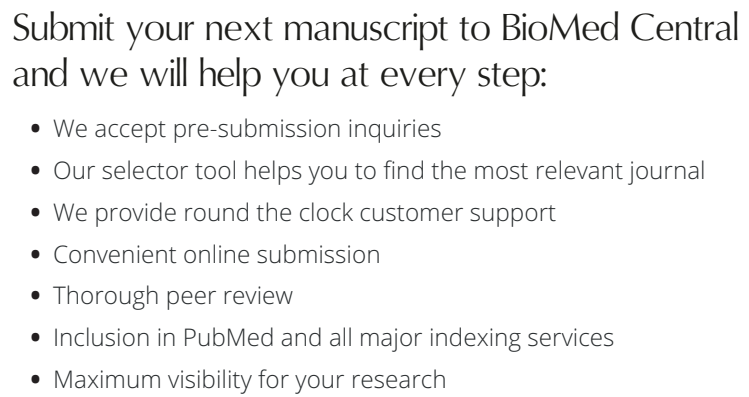

- We accept pre-submission inquiries

- Our selector tool helps you to find the most relevant journal

- We provide round the clock customer support

- Convenient online submission

- Thorough peer review

- Inclusion in PubMed and all major indexing services

- Maximum visibility for your research

Submit your manuscript at www.biomedcentral.com/submit 